\title{
Computational Thermodynamic Approach to Predict CRUD Formation
}

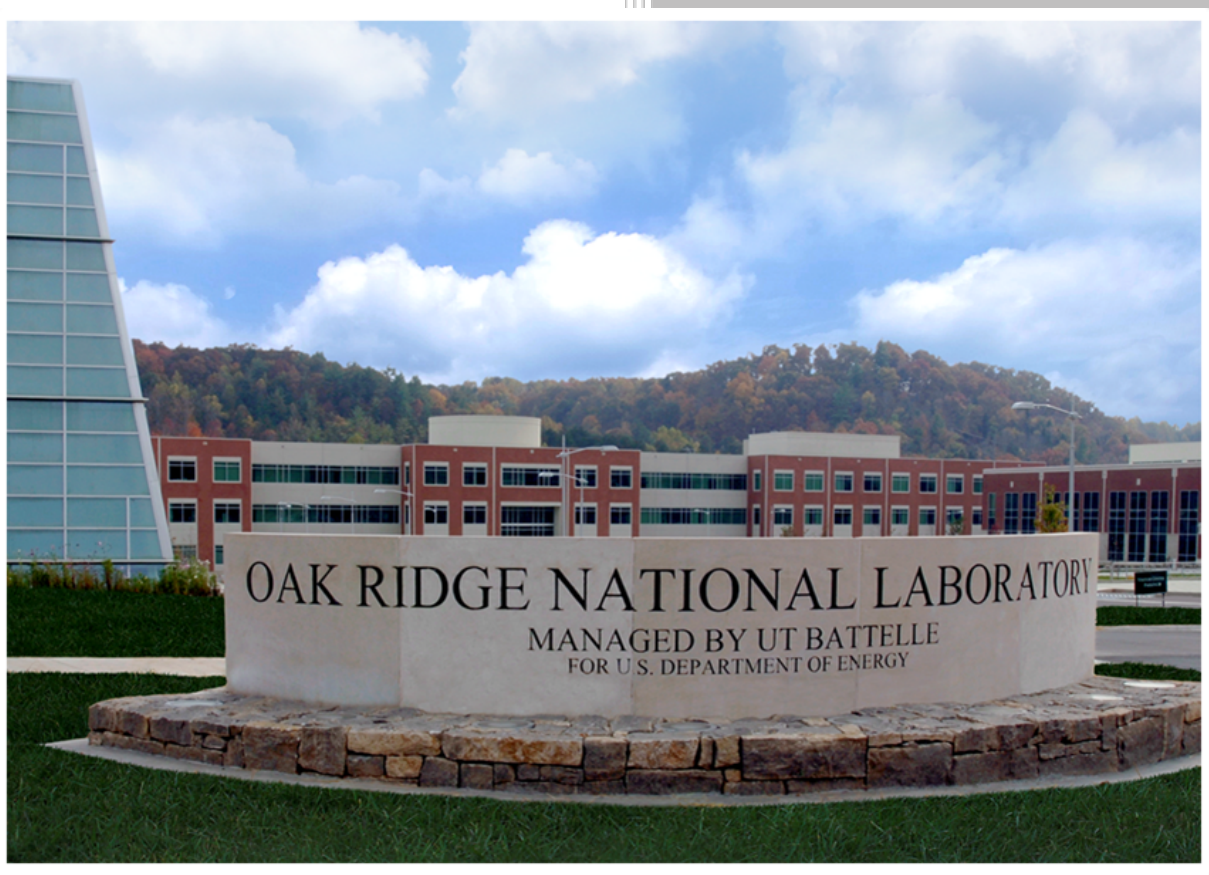

Approved for public release. Distribution is unlimited.

Dongwon Shin

July, 2016 


\title{
DOCUMENT AVAILABILITY
}

Reports produced after January 1, 1996, are generally available free via US Department of Energy (DOE) SciTech Connect.

Website http://www.osti.gov/scitech/

Reports produced before January 1,1996, may be purchased by members of the public from the following source:

\author{
National Technical Information Service \\ 5285 Port Royal Road \\ Springfield, VA 22161 \\ Telephone 703-605-6000 (1-800-553-6847) \\ TDD 703-487-4639 \\ Fax 703-605-6900 \\ E-mail info@ntis.gov \\ Website http://www.ntis.gov/help/ordermethods.aspx
}

Reports are available to DOE employees, DOE contractors, Energy Technology Data Exchange representatives, and International Nuclear Information System representatives from the following source:

Office of Scientific and Technical Information

PO Box 62

Oak Ridge, TN 37831

Telephone 865-576-8401

Fax 865-576-5728

E-mail reports@osti.gov

Website http://www.osti.gov/contact.html

This report was prepared as an account of work sponsored by an agency of the United States Government. Neither the United States Government nor any agency thereof, nor any of their employees, makes any warranty, express or implied, or assumes any legal liability or responsibility for the accuracy, completeness, or usefulness of any information, apparatus, product, or process disclosed, or represents that its use would not infringe privately owned rights. Reference herein to any specific commercial product, process, or service by trade name, trademark, manufacturer, or otherwise, does not necessarily constitute or imply its endorsement, recommendation, or favoring by the United States Government or any agency thereof. The views and opinions of authors expressed herein do not necessarily state or reflect those of the United States Government or any agency thereof. 


\section{FY16 L3 Milestone Report}

\section{Computational Thermodynamic Approach to Predict CRUD Formation}

\section{Milestone:}

Generate an open aqueous database with aqueous species and precipitates for CRUD stability and exercise the database in thermochemical calculations to predict the solubility

\section{Deliverable:}

Thermodynamic database and tables with aqueous species and precipitate phases within the CRUD

\section{Scope Description:}

The CALPHAD (CALculation of PHAse Diagram) approach will be employed to predict the thermochemistry of CRUD at high temperature and pressure in LWR/PWRs. Free energy descriptions of aqueous species using HKF (Helgeson-Kirkham-Flowers) model [1] from the SUPCRT 2007 database [2] will be converted to create an open aqueous thermodynamic database. The aqueous database will be consistent with the existing computational thermodynamic infrastructure, and thus it will facilitate to consider a large number of oxide/hydroxide phases that may form in the coolant. First-principles total energies of precipitates whose thermodynamic descriptions are not readily available in the existing databases, e.g., bonaccordite and porous nickel ferrite clusters from NCSU, will be incorporated into the open database to predict their solubilities. The calculated CRUD thermodynamics will be then used as input for MAMBA simulations to search for bonaccordite formation.

\section{Constructing Open Aqueous Database:}

Commercial CALPHAD software packages provide aqueous databases (e.g., AQS2 as implemented in Thermo-Calc) that support HKF model and allow calculating thermodynamic properties of aqueous solutions at conditions of temperatures up to $1000^{\circ} \mathrm{C}$, pressures up to $5 \mathrm{kbar}$, and aqueous concentrations up to 6 molality (at room temperature and pressure) or higher (at high temperature and pressure). Within the context of the CALPHAD approach, it is possible to predict the phase stability of complex multicomponent aqueous system by extrapolating parameters of critically evaluated and assessed binary and ternary systems. However, model parameters of individual phases and species within such proprietary databases are often encrypted. Hence, it is not possible to adjust parameters to replicate critical experiments when there is a discrepancy between predicted and observed values.

Due to the fact that most of thermochemical model parameters in the proprietary database have not been critically validated against thorough experiments, there is a possibility that they need to be adjusted in the future. This task focuses on creating a flexible open aqueous database --- whose model parameters can be flexibly adjusted --- that can predict thermochemical properties of complex aqueous solutions including the solubility of CRUD.

Thermo-Calc offers an open aqueous database (PAQS2) that supports the HKF model with a limited number of elements. Although most of aqueous species are missing relevant to CRUD, it can serve as a place holder for an open aqueous database. We used the ASU GEOPIG database ${ }^{1}$ and SGTE (Scientific Group Thermodata Europe) substance (SSUB) database to add thermochemical model parameters for missing phases and missing aqueous species ( $\mathrm{Li}, \mathrm{B}$ containing species) along with phases that are relevant with the precipitation of CRUD on top the PAQS2 database. Using this approach, it should be possible to generate a sufficiently complete database to properly predict solubilities of important phases.

\footnotetext{
${ }^{1}$ http://geopig.asu.edu/sites/default/files/slop07.dat
} 


$$
\begin{aligned}
\Delta \bar{G}_{P, T}^{o}= & \Delta \bar{G}_{\mathrm{f}}^{o}-\bar{S}_{P t, T r}^{o}\left(T-T_{r}\right)-c_{1}\left(T \ln \left(\frac{T}{T_{r}}\right)-T+T_{r}\right) \\
& -c_{2}\left(\left[\left(\frac{1}{T-\theta}\right)-\left(\frac{1}{T_{r}-\theta}\right]\right)\left(\frac{\theta-T}{\theta}\right)-\frac{T}{\theta^{2}} \ln \left(\frac{T_{r}(T-\theta)}{T\left(T_{r}-\theta\right)}\right)\right) \\
& +a_{1}\left(P-P_{r}\right)+a_{2} \ln \left(\frac{\Psi+P}{\Psi+P_{r}}\right)+\left(\frac{1}{T-\theta}\right)\left[a_{3}\left(P-P_{r}\right)+a_{4} \ln \left(\frac{\Psi+P}{\Psi+P_{r}}\right)\right] \\
& +\omega\left(\frac{1}{\epsilon}-1\right)-\omega_{P t, T r}\left(\frac{1}{\epsilon_{P t, T r}-1}\right)-\omega_{P t, T r} Y_{P t, T r}\left(T-T_{r}\right)
\end{aligned}
$$

The standard-state thermodynamic property of any aqueous species in water can be represented by a function with seven terms which have specific values for each species as shown in Eq. 1. These seven terms $\left(\mathrm{a}_{1-4}, \mathrm{c}_{1-2}\right.$, and $\left.\omega\right)$ are integration constants for volume (a), heat capacity (c) and temperature and pressure properties of water $(\omega)$ [2]. Publically available, all these parameters of individual aqueous species that are relevant with the CRUD precipitation in LWR/PWR have been converted into ThermoCalc compatible format and included in the construction of open aqueous database.

\section{Validation of Open Aqueous Database}

In order to validate the accuracy of the ORNL open Aqueous database developed in this work, the dissolution reaction of $\mathrm{LiBO}_{2}$ in high-temperature water has been calculated and benchmarked against available experimental results [3] and the AQS2 database. The solubility of $\mathrm{LiBO}_{2}$ in water can be represented as following isocoulombic reaction:

$$
\mathrm{LiBO}_{2}+\mathrm{H}_{(\text {aq) }}^{+}+\mathrm{H}_{2} \mathrm{O}_{(l)}=\mathrm{Li}_{(\text {aq) }}^{+}+\mathrm{H}_{3} \mathrm{BO}_{3(\mathrm{aq})}
$$

POLY-3 module as implemented in Thermo-Calc was used to calculate the activity coefficients of individual aqueous species to derive equilibrium constant, $K$. The result is plotted with experiments and they are in good agreement as shown in Figure 1. It is encouraging that thermochemical properties of complex aqueous solution can be accurately derived from the current computational approach. 


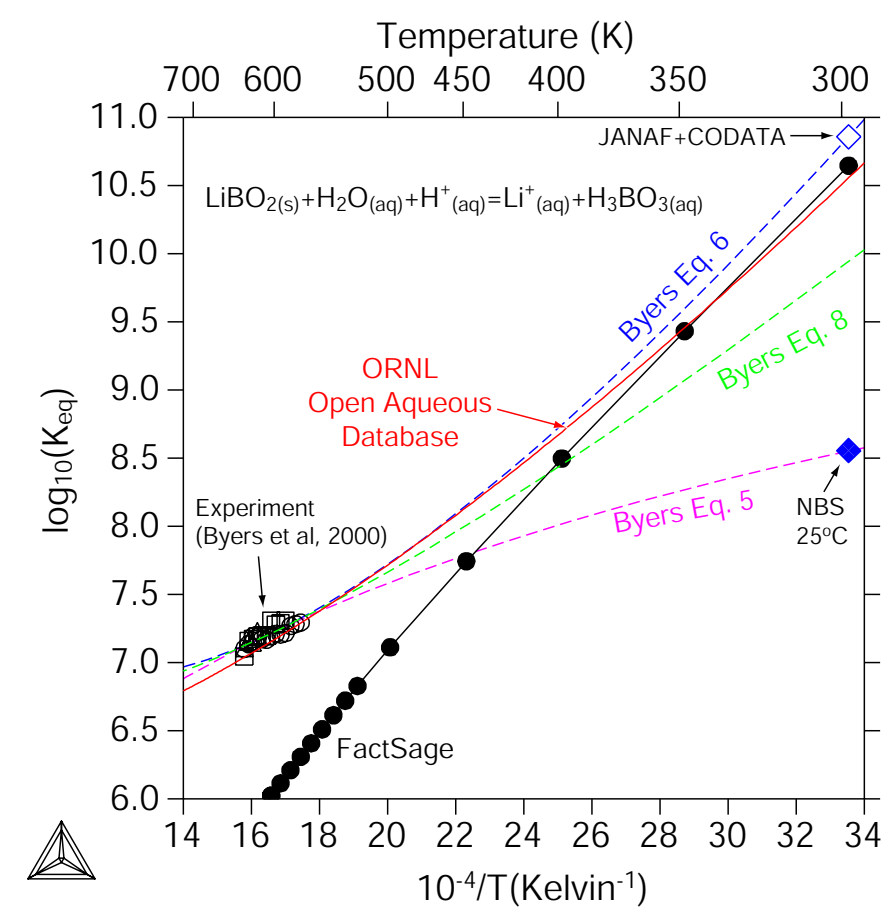

Figure 1 Calculated equilibrium constants for $\mathrm{LiBO}_{2}$ dissolution reaction from ORNL Open Aqueous database in comparison with experiments [3]

Next, we wish to benchmark the accuracy of open database against the proprietary AQS2 database from Thermo-Calc. Table 1 shows the calculated activities of aqueous species in Eq. 1 and they are in excellent agreement. This comparison shows that the current open database is as accurate as the commercial database while allowing the adjustment of model parameters when necessary.

Table 1 Calculated activities of aqueous species participating in the $\mathrm{LiBO}_{2}$ dissolution reaction from the proprietary AQS2 database as implemented in Thermo-Calc and ORNL database, respectively.

\begin{tabular}{|c|c|c|}
\hline $\log _{10} a$ & AQS2 Database & $\begin{array}{c}\text { ORNL } \\
\text { Open Database }\end{array}$ \\
\hline $\mathrm{H}_{2} \mathrm{O}$ & $1.176977 \mathrm{E}-2$ & $1.1756749 \mathrm{E}-2$ \\
\hline $\mathrm{H}^{+}$ & -6.5679188 & -6.5679135 \\
\hline $\mathrm{Li}^{+}$ & 1.4633286 & 1.4669439 \\
\hline $\mathrm{H}_{3} \mathrm{BO}_{3}$ & -0.30784258 & -0.3078346 \\
\hline
\end{tabular}

From the created open database, we wish to calculate the solubility of lithium mono- and tetra-borates $\left(\mathrm{LiBO}_{2}\right.$ and $\left.\mathrm{Li}_{2} \mathrm{~B}_{4} \mathrm{O}_{7}\right)$ in water under 155 bar as a function of temperature as is presented in Figure 2. Experimentally measured solubility of $\mathrm{LiBO}_{2}$ from Byers et al. [3] is plotted with the calculated results. 


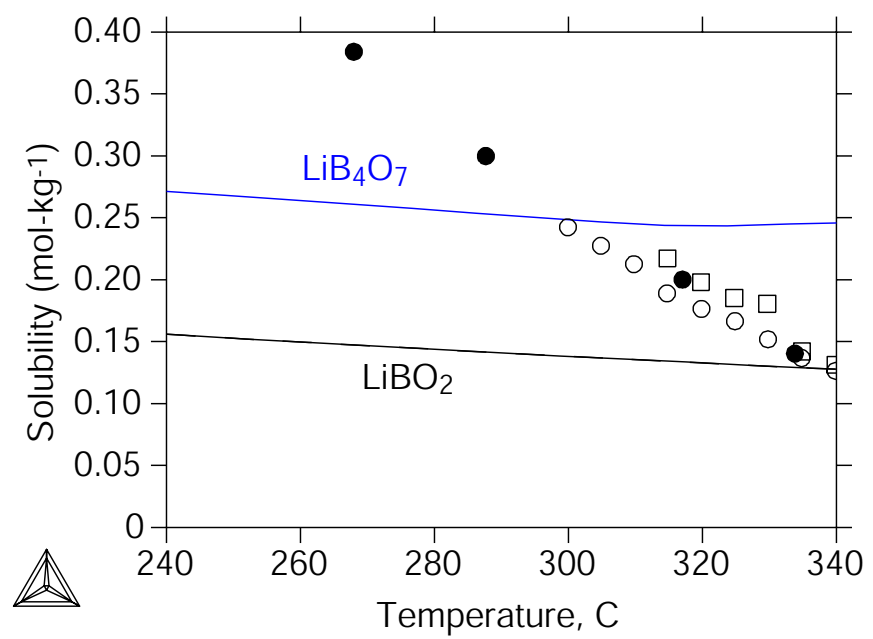

Figure 2 Calculated solubilities of $\mathrm{LiBO}_{2}$ and $\mathrm{Li}_{2} \mathrm{~B}_{4} \mathrm{O}_{7}$ in water at the pressure of 155 bar from the open aqueous database created in the present work. Symbols represent the experimentally determined solubility of $\mathrm{LiBO}_{2}$ [3].

There is a notable discrepancy between the calculated and experimental solubility of $\mathrm{LiBO}_{2}$ in water; the current model underestimates the solubility at low temperatures. Although thermodynamic descriptions of individual phases and aqueous species are accurate within the experimental error range, further adjusting of model parameters is usually required to self-consistently reproduce phase equilibrium data. However, such an effort requires much more comprehensive experimental exploration of large compositional space at a given temperature, which is beyond the scope of current work package. Nevertheless, the present task provides a groundwork to develop a high-fidelity aqueous thermochemistry model to predict conditions to form CRUD in $L W R / P W R$ when critical experimental dataset is available.

\section{Evaluating Gibbs Free Energy of Bonaccordite Phase}

Next, we evaluate finite-temperature thermodynamic description of bonaccordite $\left(\mathrm{Ni}_{2} \mathrm{FeBO}_{5}\right)$ to be included in the aqueous calculations.

$$
\begin{aligned}
\mathrm{G}\left(\mathrm{Ni}_{2} \mathrm{FeBO}_{5}\right) & =2 \mathrm{G}^{\mathrm{fcc}}(\mathrm{Ni})+\mathrm{G}^{\mathrm{bcc}}(\mathrm{Fe})+\mathrm{G}^{\mathrm{rhombo}}(\mathrm{B})+\frac{5}{2} \mathrm{G}^{\mathrm{Gas}}\left(\mathrm{O}_{2}\right) \\
& +\Delta H_{f}\left(-T \Delta S_{f}\right)
\end{aligned}
$$

An initial parameter, particularly formation enthalpy at room temperature $\left(\Delta H_{f}\right)$, has been obtained from the first-principles total energy calculations based on density functional theory (DFT) provided by NCSU [4]. Formation entropy has not been introduced for the sake of simplicity. However, it was found that entropy at room temperature $\left(\mathrm{S}_{298 \mathrm{~K}}\right)$ of bonaccordite was too high in comparison with similar other oxide phases. Hence, we evaluated $\Delta S_{f}\left(\mathrm{Ni}_{2} \mathrm{FeBO}_{5}\right)$ from the estimated $\mathrm{S}_{298 \mathrm{~K}}\left(\mathrm{Ni}_{2} \mathrm{FeBO}_{5}\right)$ based on the 'Latimer' approximation approach [5], which separately takes into account ionic contribution to the entropy of solid states. As shown in Table 2, estimated $\mathrm{S}_{298 \mathrm{~K}}$ of select oxides are in good agreement with the same values evaluated from the SSUB database.

Table 2 Estimated $\mathrm{S}_{298 \mathrm{~K}}$ values of select oxide phases from the 'Latimer' approach [5] in comparison with the values from the SSUB database. The averaged values of the 'Latimer' estimation have been used to take into account error bar associated with the cations.

\begin{tabular}{ccc}
\hline \multirow{2}{*}{ Oxide phase } & \multicolumn{2}{c}{$\mathrm{S}_{298 \mathrm{~K}}(\mathrm{~J} / \mathrm{mol}-\mathrm{K})$} \\
& 'Latimer' approach & SSUB \\
\hline $\mathrm{SrTiO}_{3}$ & 95.2 & 109.0
\end{tabular}




$\begin{array}{ccc}\mathrm{Fe}_{2} \mathrm{NiO}_{4} & 117.9 & 125.9 \\ \mathrm{Al}_{2} \mathrm{Sr}_{3} \mathrm{O}_{6} & 269.1 & 255.4 \\ \mathrm{Cr}_{2} \mathrm{NiO}_{4} & 113.7 & 119.2 \\ \mathrm{MgTi}_{2} \mathrm{O}_{5} & 137.5 & 125.2 \\ \mathrm{Ni}_{2} \mathrm{FeBO}_{5} & 164.2 & \end{array}$

In addition to evaluating $\Delta S_{f}\left(\mathrm{Ni}_{2} \mathrm{FeBO}_{5}\right)$, binary oxides (i.e., $\mathrm{NiO}, \mathrm{Fe}_{2} \mathrm{O}_{3}$, and $\left.\mathrm{B}_{2} \mathrm{O}_{3}\right)$ instead of pure elements have been used as reference states to better describe heat capacity based on the Nuemann-Kopp additivity rule of bonaccordite as well. Thermodynamic properties of bonaccordite from the evaluated model parameters are presented in Figure 3.
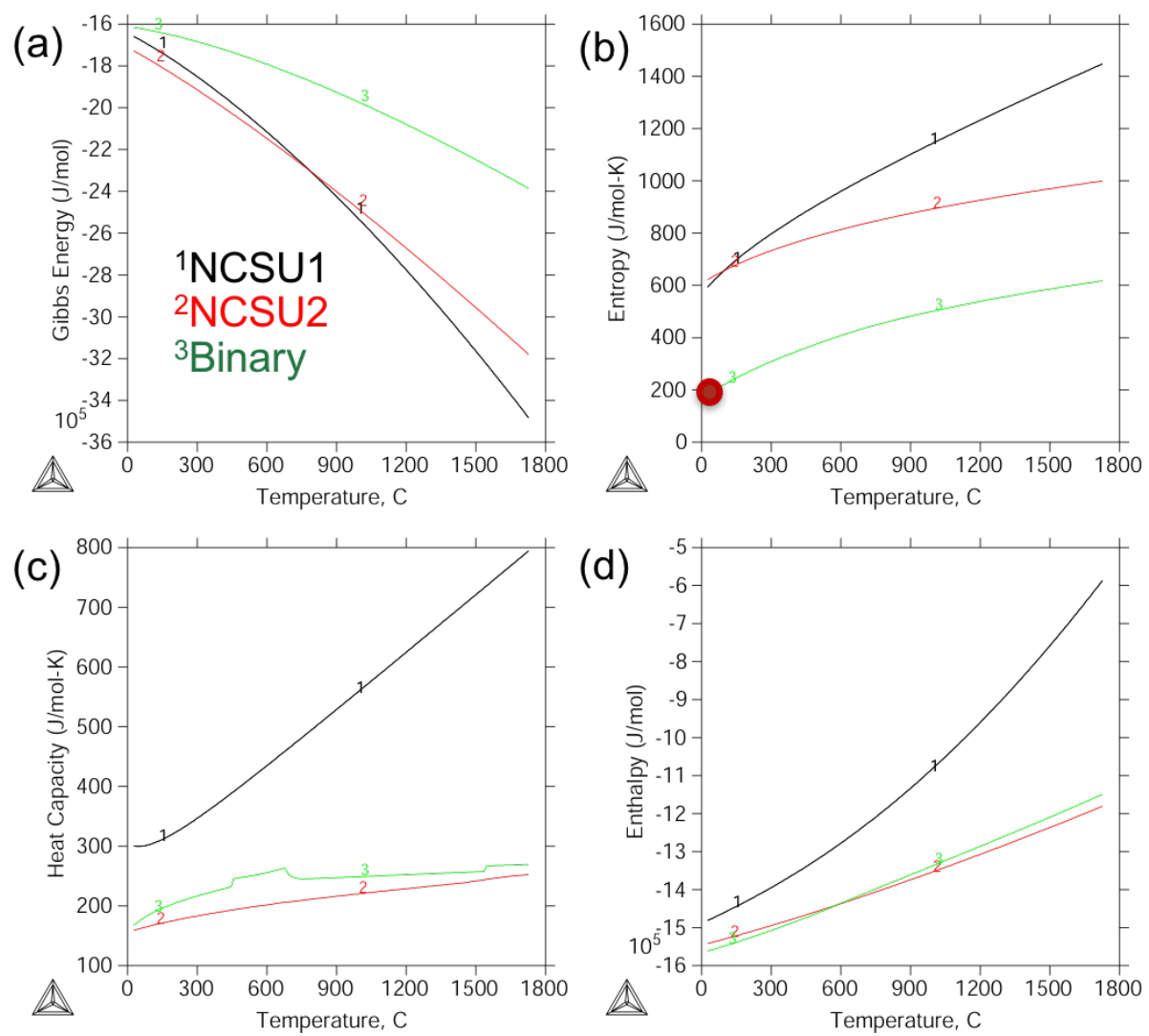

Figure 3 Calculated finite-temperature thermodynamic properties of bonaccordite: (a) Gibbs free energy, (b) entropy, (c) heat capacity and (d) enthalpy. DFT total energy and estimated $S_{298 \mathrm{~K}}$ from the 'Latimer' approach of have been used to evaluate enthalpy and entropy of formation, respectively. 


\section{Solubility Calculations for PWR Coolant Containing Fe, Ni, Li and B:}

A series of preliminary equilibrium calculations performed using POLY-3 Gibbs energy minimizer module as implemented in Thermo-Calc to investigate the formation of CRUD in water. We wish to construct a comprehensive aqueous phase diagram as a function of metal concentration and temperature by fully exploiting the predictive capability of the computational thermodynamic approach based on an extrapolation scheme. However, an attempt to map the phase stabilities as a function of two-dimensional elemental compositions was not successful due to a numerical convergence issue. On the other hand, we could manage to run a series of step calculations as a function of temperature at given elemental concentration. We considered $1 \mathrm{~kg}$ of water at 155 bar pressure with arbitrary composition of $\mathrm{Fe}, \mathrm{Ni}, \mathrm{Li}$ and $\mathrm{B}$.

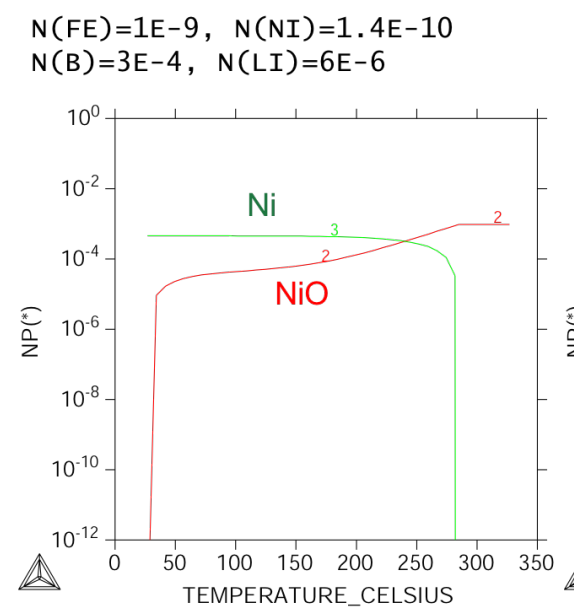

$N(F E)=1 E-9, N(N I)=1.4 E-11$

$N(B)=3 E-4, \quad N(L I)=6 E-6$

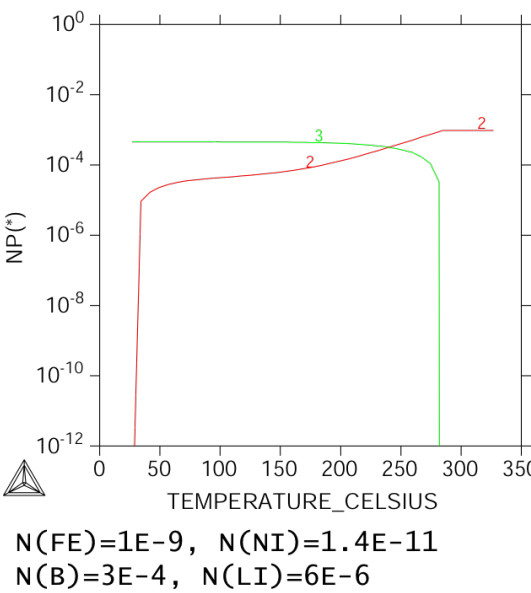

$N(F E)=1 E-9, N(N I)=1,4 E-10$

$N(B)=3 E-4, N(L I)=6 E-6$

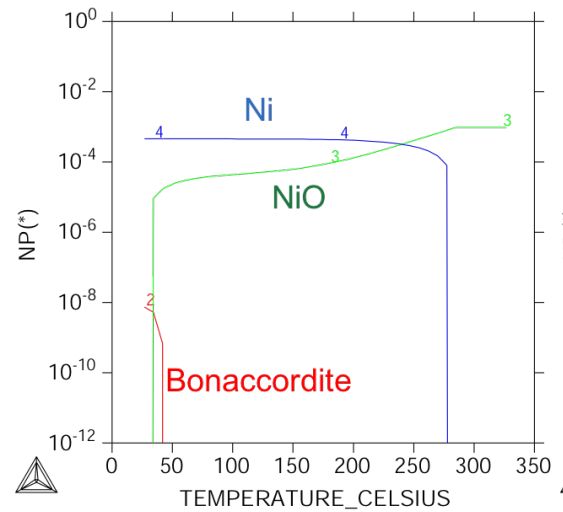

$N(B)=3 E-4, N(L I)=6 E-6$

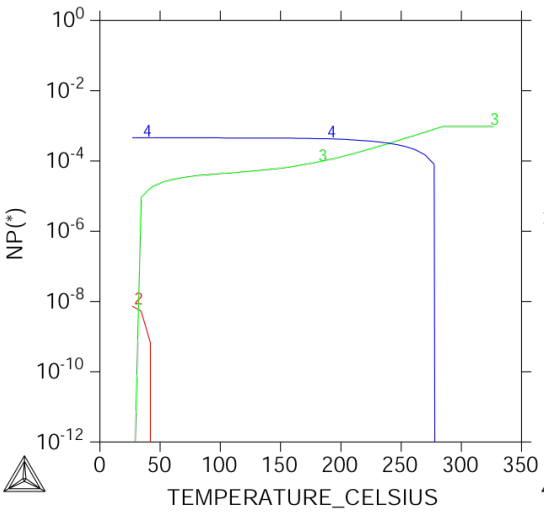

$N(F E)=1 E-9, N(N I)=1.4 E-10$

$N(B)=3 E-3, N(L I)=6 E-6$

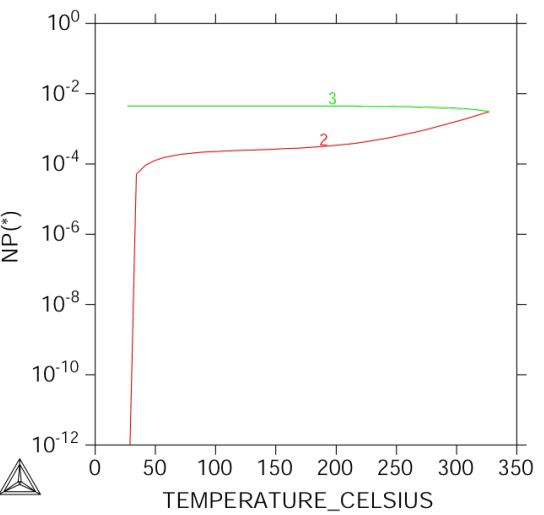

$N(F E)=1 E-9, N(N I)=1.4 E-10$

$N(B)=3 E-3, N(L I)=6 E-6$

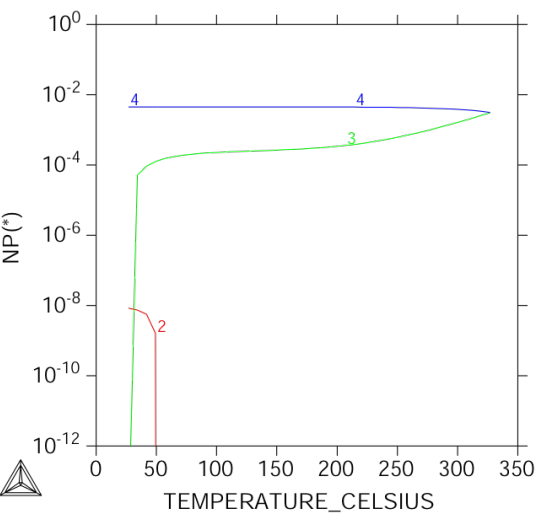

Figure 4 Calculated phase fraction of precipitate phases at arbitrary concentrations of $\mathrm{Fe}, \mathrm{Ni}, \mathrm{Li}$ and $\mathrm{B}$ with (top) adjusted and (bottom) unadjusted Gibbs free energy of bonaccordite.

We started with a series of point equilibrium calculations with different elemental compositions. The major precipitate phases predicted with dilute elemental composition were $\mathrm{Ni}$ metal and $\mathrm{NiO}$ as shown in Figure 4. The calculated diagram shows that the precipitation of bonaccordite is highly sensitive to the Gibbs energy model parameters used within the equilibrium calculations.

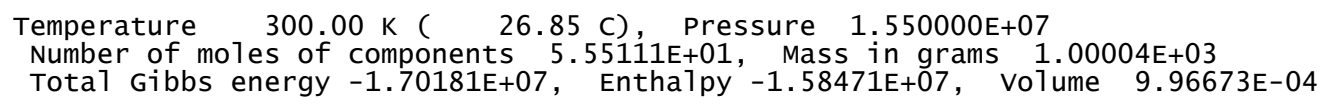




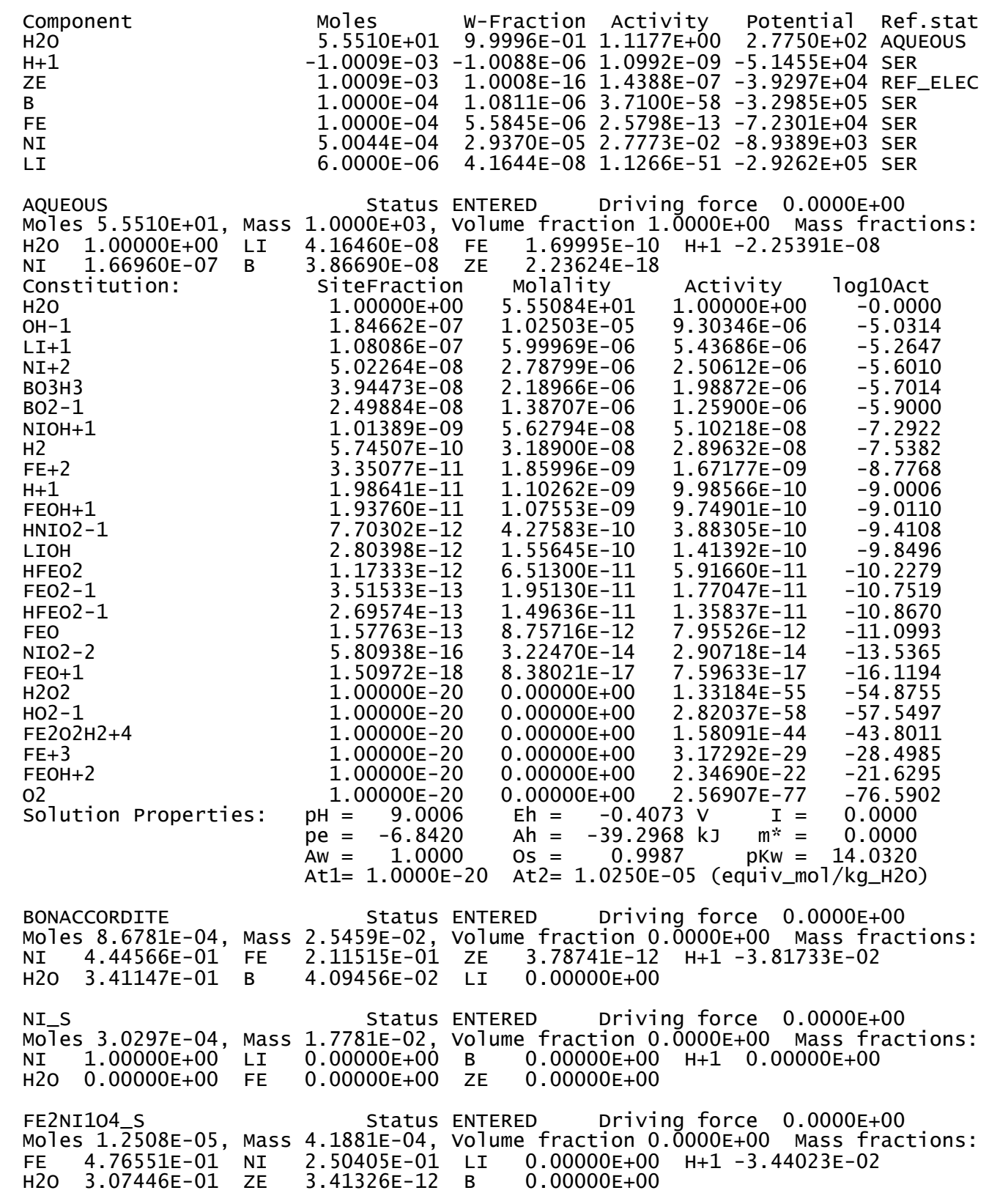

It was found that the formation of nickel ferrite was not predicted unless the concentration of $\mathrm{Fe}$ and $\mathrm{Ni}$ is relatively high $\left(10^{-4}\right)$ at low temperatures. The point equilibrium calculations at low temperatures and high $\mathrm{Fe} / \mathrm{Ni}$ concentration predicted the co-precipitation of nickel ferrite and bonaccordite when unadjusted Gibbs free energy of bonaccordite was used. Even with the erroneous energetics of bonaccordite, its precipitation was only predicted at low temperatures as shown in Figure 4. 


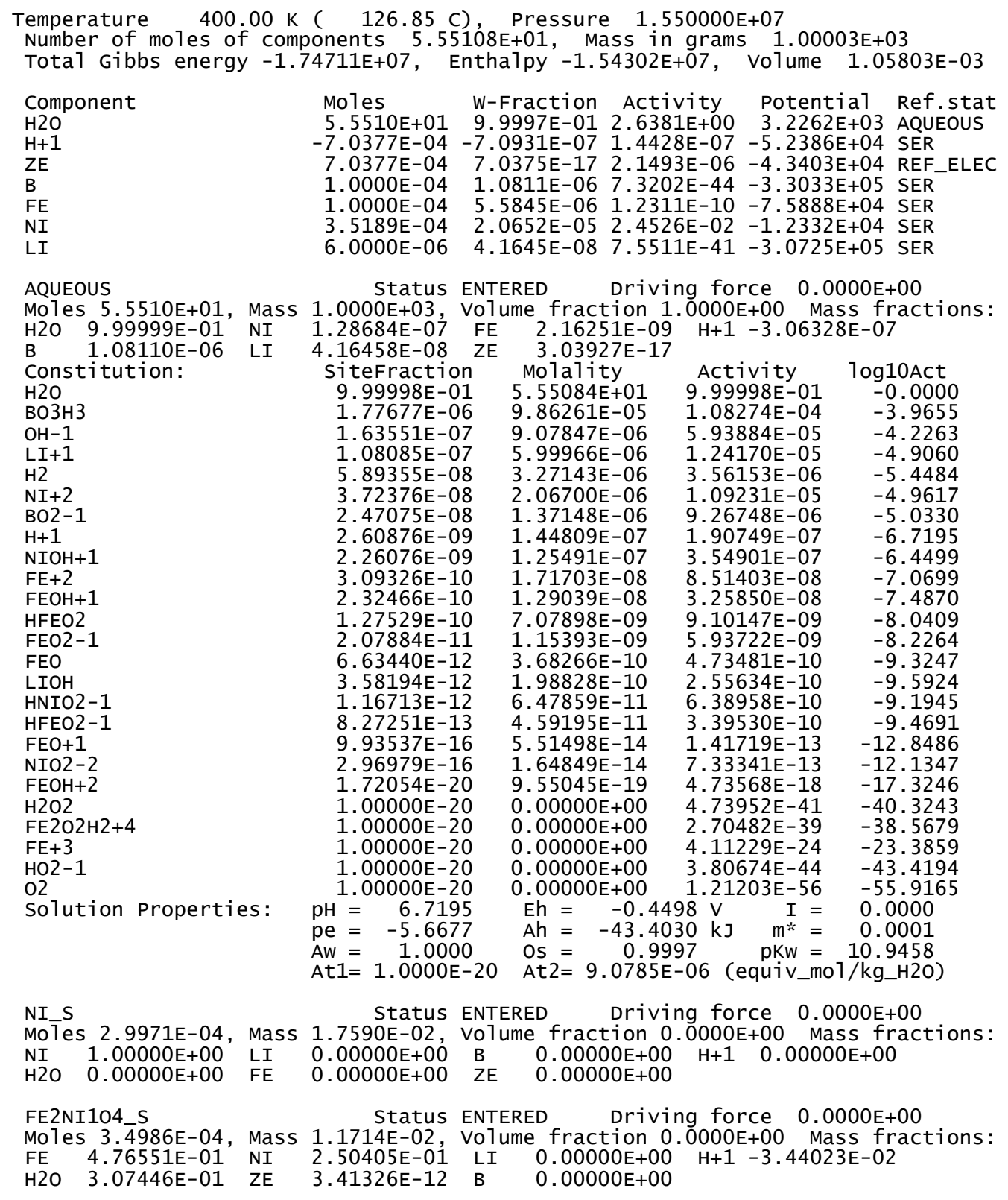

As temperature increases, the precipitation of nickel ferrite was predicted even with a smaller amount of $\mathrm{Ni}$ and Fe concentration $\left(\sim 10^{-7}\right)$. This is consistent with experimental observation that the formation of CRUD occurs near the boiling temperature. However, the formation of bonaccordite at elevated temperatures was not predicted.

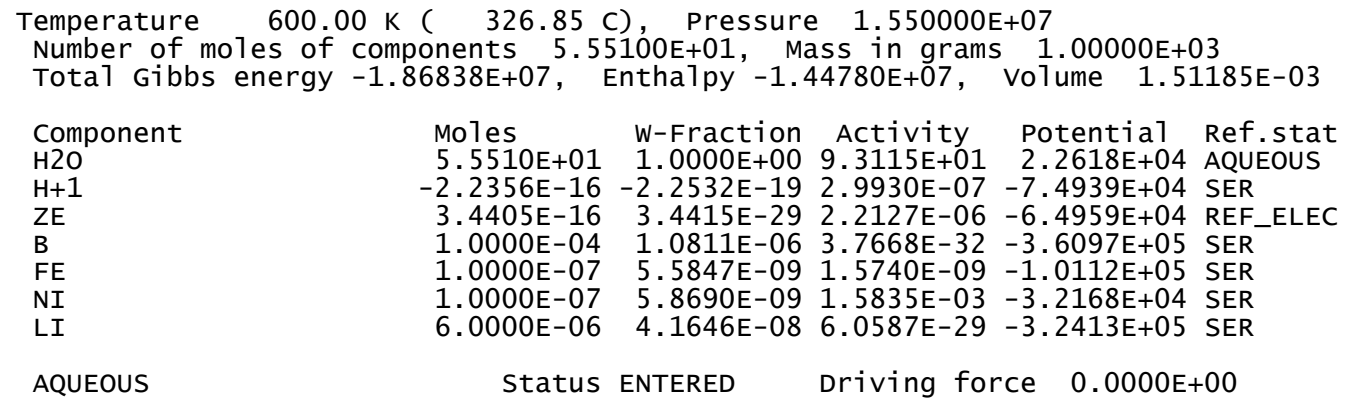




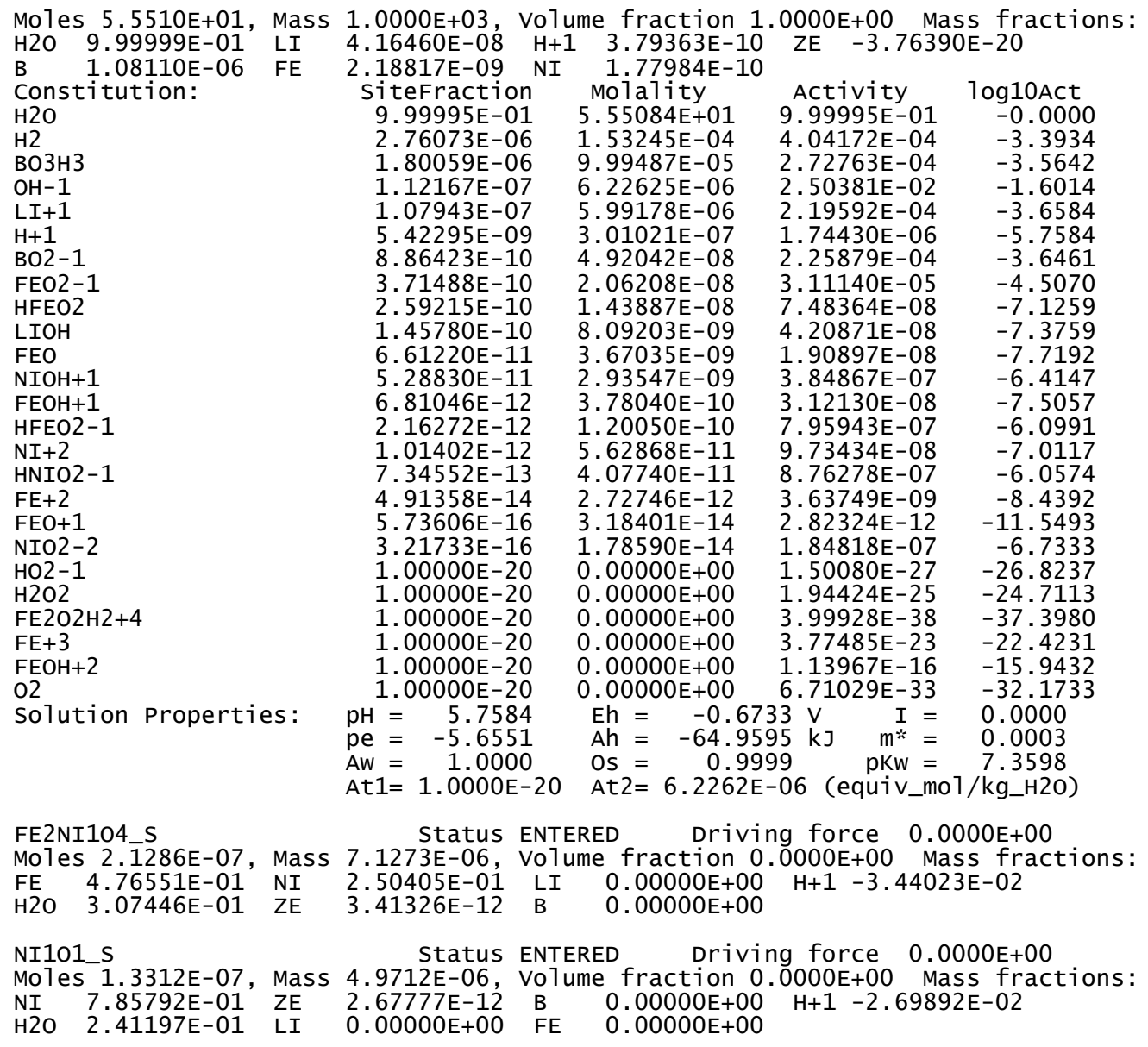

\section{Summary}

The current project exploited computational thermodynamic modeling approach to predict the solubility of CRUD in high-temperature water pertinent to LWR/PWR conditions. An ORNL open aqueous database that support the HKF model has been successfully created from the ASU GEOPIG database containing $\mathrm{Fe}, \mathrm{Ni}, \mathrm{Zn}, \mathrm{Li}$ and $\mathrm{B}$. All the phases and aqueous species that are relevant to precipitation of CRUD in LWR/PWR have been included in the database including nickel ferrite and bonaccordite. The computation results from the aqueous database using Thermo-Calc showed that formation of major CRUD constituent, nickel ferrite, is only favored when the concentration of $\mathrm{Ni}$ and $\mathrm{Fe}$ is sufficiently high enough at low temperatures. Near the boiling temperature, critical amount for metals for oxide precipitation was lower than that of lower temperatures. The precipitation of bonaccordite has been predicted only when the temperature range is relatively low. It has been also shown that that phase stabilities of oxide precipitates and aqueous species are quite sensitive to model parameters used within and further experimental validation maybe needed. This project established a ground work to incorporate critical experiments in the future to reevaluate thermodynamic model parameters of CRUD phases and aqueous species to accurately predict aqueous thermochemistry relevant to LWR/PWR coolant system. 


\section{References}

[1] H.C. Helgeson, D.H. Kirkham, G.C. Flowers, Theoretical prediction of the thermodynamic behavior of aqueous electrolytes by high pressures and temperatures; IV, Calculation of activity coefficients, osmotic coefficients, and apparent molal and standard and relative partial molal properties to 600 d, Am. J. Sci. 281 (1981) 1249-1516. doi:10.2475/ajs.281.10.1249.

[2] E.L. Shock, H.C. Helgeson, Calculation of the thermodynamic and transport properties of aqueous species at high pressures and temperatures: Correlation algorithms for ionic species and equation of state predictions to $5 \mathrm{~kb}$ and $1000^{\circ} \mathrm{C}$, Geochim. Cosmochim. Acta. 52 (1988) 2009-2036. doi:10.1016/0016-7037(88)90181-0.

[3] W.A. Byers, W.T. Lindsay, R.H. Kunig, Solubility of Lithium Monoborate in High- Temperature Water, J. Solution Chem. 29 (2000) 541-559.

[4] Z. Rak, C.J. O'Brien, A. Andersson, D.W. Brenner, D. Shin, C.R. Stanek, Theoretical Assessment of Bonaccordite formation in Pressurized Water Reactors, J. Nucl. Mater. 474 (2016) 62-64. doi:10.1016/j.jnucmat.2016.02.016.

[5] P.J. Spencer, Estimation of thermodynamic data for metallurgical applications, Thermochim. Acta. 314 (1998) 1-21. doi:10.1016/S0040-6031(97)00469-3. 